\title{
ANÁLISE DA TEMPERATURA DO SOLO ABAIXO DA COPA DE TRÊS ESPECIES DE ÁRVORES NA CIDADE DE SERRA TALHADA - PE
}

\author{
Wellington Jorge Cavalcanti Lundgren ${ }^{1}$, Luzia Ferreira da Silva², \\ Thialla Laranjeira Amorim ${ }^{3}$, Kaline Pereira dos Santos Silva ${ }^{4}$
}

\section{RESUMO}

Medidas de temperatura do solo abaixo da copa de árvores de três espécies, Ficus benjamina L (fícus) Azadirachta indica A. Juss (nin) e Acacia farnesiana L. (acássia) foram realizadas, o objetivo foi a verificação da existência de diferença na temperatura abaixo das copas e na amplitude térmica entre as espécies e entre o tamanho das copas, quanto ao tamanho as árvores foram divididas em dois grupos, copas grandes e pequenas. Um semivariograma da temperatura do solo abaixo da copa de uma árvore de fícus foi construído para verificar a existência de dependência espacial e um mapa foi produzido pela krigagem. Não foram detectadas diferenças significativas para a temperatura do solo nem para as espécies nem para os tamanhos das copas. Foi detectada diferença significativa pelo teste de Tukey ao nível de 5\% tanto para as espécies como para as dimensões das copas quando o atributo amplitude térmica do solo. A temperatura do solo apresentou forte dependência espacial, e constatou-se que a amplitude térmica entre a temperatura do solo próxima ao tronco da árvore e na calçada de paralelepípedo exposta diretamente ao sol ultrapassa $30^{\circ} \mathrm{C}$.

Palavras-chave: Amplitude térmica; Semiárido; Cidades; Urbanização; Arborização. 


\title{
ANALYSIS OF SOIL TEMPERATURE BELOW THE CUP OF THREE SPECIES OF TREES IN SERRA TALHADA CITY IN PERNAMBUCO STATE
}

\begin{abstract}
ABSTRAT
Measurements of soil temperature below the treetops of three species, Ficus benjamina $\mathrm{L}$, Azadirachta indica A. Juss and Acacia farmesiana L. were performed. The goal was checking the existence of temperature difference below the treetops and in the thermal amplitude between species and between the size of their cups. Regarding the size, the trees were classified into two groups: small and large treetops. A semivariogram of the soil temperature below the treetop of a Ficus tree was built to verify the existence of spatial dependence and a map was created using kriging. Neither significant differences to soil temperature nor to the species nor to the sizes of treetops were found. A significant difference was detected using the Tukey test at a level of $5 \%$ to either the species or for the treetops dimensions when the attribute was temperature range of the soil. The soil temperature showed strong spatial dependence, and it was found that the thermal amplitude between the soil temperature close to the trunk of the tree and on the cobblestone sidewalk

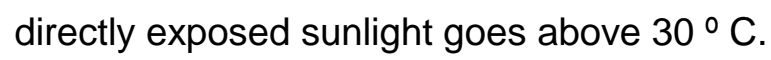

Keywords: Temperature range; Semiarid; Cities; Urbanization; Afforestation.

\section{INTRODUÇÃO}

Ao longo dos anos a maioria das cidades em todo o mundo cresceu em população e em área de forma exponencial. $O$ crescimento das cidades consequentemente traz consigo maior área coberta com calçadas, cimento e concreto, diminuindo a área de absorção da água da chuva acompanhada da diminuição de fornecimento de água para o lençol freático e de uma drástica, quase que total eliminação da área verde que antes ali havia e que recebia a radiação solar, amenizando o aquecimento do ar na região. É de conhecimento da física que os raios solares não aquecem o ar diretamente, os raios solares aquecem as superfícies sólidas e líquidas por irradiação e esses aquecem o ar por condução e convecção. 
O crescimento das cidades em área provoca o aquecimento do ar, e quanto maior a cidade mais esse problema se agrava. Mendonça e Dubreuil (2005) construíram um mapa de temperatura do ar para o município de Curitiba - PR e arredores e constataram que a temperatura na zona urbana era maior que na zona rural.

É consenso entre os estudiosos do meio ambiente urbano que a arborização e o aumento das áreas verdes nas cidades é acompanhado de melhorias consideráveis no bem estar das pessoas. Alguns trabalhos (GOMES; SOARES, 2003; SHAMS et al., 2009) comprovam a melhoria na sensação de bem estar que uma arborização adequada provoca nas pessoas.

Lundgren et al. (2013) verificaram que na cidade de Serra Talhada - PE localizada no semiárido nordestino onde a temperatura é alta e a umidade é bem pequena, o uso da arborização no meio urbano que deveria ser uma das prioridades tanto do poder público como da própria população, mas infelizmente não é o que se observa. A prefeitura é completamente alheia ao problema, e o plantio, a escolha das espécies, o número de árvores existentes e os locais onde são plantadas ficam a cargo e ao gosto da população.

$\mathrm{Na}$ cidade de Serra Talhada - PE, o clima é rigoroso em termos de altas temperaturas e umidade relativa do ar e a insolação é intensa, fazendo com que a arborização urbana passe a ser um problema inclusive de saúde pública. Gouvéia (1999) associa algumas doenças ao crescimento das cidades e cita que o aumento de temperatura pode provocar diversos problemas, entre eles, o aumento do número de infartos e de pessoas com hipertensão. Porém, na maioria das cidades o descaso é quase que total por parte do poder público.

O censo da arborização das calçadas da cidade de Serra Talhada - PE foi realizado por Lundgren et al. (2012) e forneceu dados preocupantes. A cidade possuía até 2012 algo em torno de 8600 árvores em suas calçadas, sendo que aproximadamente 6000 eram Ficus benjamina L., 1600 Azadirachta indica A. Juss e 600 Acacia L., representando 96\% do total de indivíduos arbóreos do município, sendo que somente o restante das árvores pertencem as outras espécies.

Foi então percebido que a cidade é praticamente arborizada por apenas três espécies e para agravar a situação $98 \%$ das árvores são podadas sistematicamente assim que suas alturas começam a chegar perto da altura da rede elétrica ou então suas copas são podadas em forma cilíndrica ou cúbica ao atingirem um tamanho que na média, corresponde a um raio de copa de 2,38 metros. O pequeno número de árvores e o hábito da poda sistemática faz com que grande parte da cidade fique descoberta, recebendo a 
insolação direta nos paralelepípedos, asfalto ou cimento das calçadas o que provoca o aquecimento do ar de forma intensa.

Diante do exposto, os objetivos desse trabalho foram comparar a temperatura do solo e a amplitude térmica do solo abaixo das copas das três espécies dominantes na cidade, Ficus benjamina L, Azadirachta indica A. Juss e Acacia farnesiana L., também para o tamanho das copas, além de construir o mapa dessa temperatura para a espécie dominante na cidade, que é o fícus com aproximadamente 2,38 metros de raio de copa.

\section{MATERIAIS E MÉTODOS}

Na latitude 0759'31" Sul e longitude 38¹7'54" Oeste, encontra-se a cidade de Serra Talhada localizada na Mesorregião do Sertão pernambucano na Microrregião do Pajeú, a uma altitude de 429 metros (M.M.E, 2005), com uma população estimada em torno de 80.000 habitantes (IBGE, 2010b).

Uma equipe de dois pesquisadores utilizando uma fita métrica de 20 metros e um termômetro infravermelho 1.2 LCD, mediram a temperatura do solo em volta de nove árvores nas calçadas das ruas da cidade, três árvores da espécie Ficus benjamina L. (fícus), três da espécie Senna siamea L. (acássia) e três da espécie Azadirachta indica A. Juss (nin).

As disposições das medidas em volta das árvores obedeceram aos seguintes critérios, o raio da copa foi medido e dividido por seis, o resultado forneceu o espaçamento entre uma medição e outra. Ao redor do tronco foram traçados oito raios igualmente espaçados entre si com $45^{\circ}$, como pode ser visto na Figura 01 , acompanhando os raios foram realizadas nove medições de temperatura do solo igualmente espaçadas, seis abaixo da copa (na sombra) e três fora da copa (exposto ao sol). Em alguns casos os muros das casas não permitiram a realização de todas as medições. Cada medida foi localizada em um plano cartesiano como um ponto (X, Y) (Figura 1).

Foram anotados o dia da medição, o nome da rua, o número da casa em que a árvore estava em frente, a hora do início da medição, a hora do término da medição, a espécie e a temperatura do solo. Todas as medições ocorreram entre as 11:30 e 12:30 hs com a intenção de que a inclinação do sol fosse a menor possível no momento da medição, de forma que o perímetro da copa coincidisse da maneira mais precisa possível com a área da sombra. 
Figura 1. Esquema das medições abaixo da árvore

Figure 1. Scheme of measurements below the tree

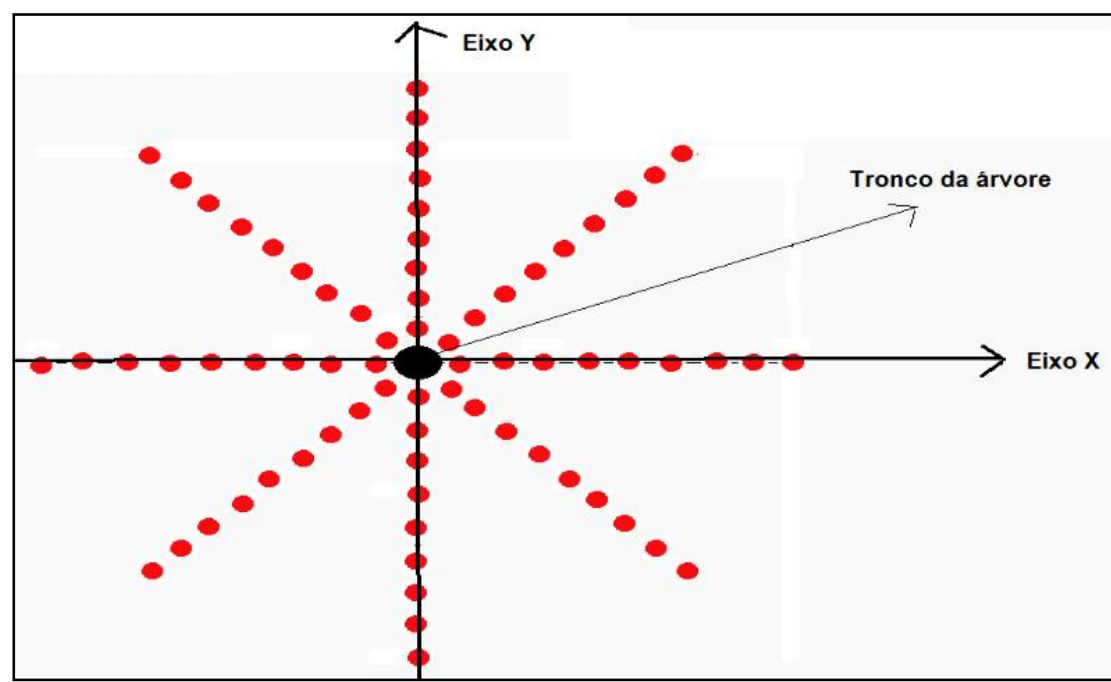

Nota: Os pontos vermelhos são os locais das medições. Nas linhas todos tem a mesma distância entre um e outro

\section{a) Estatística clássica}

A análise de variância e o teste de Tukey foram utilizados para comparar as temperaturas do solo abaixo da copa (TSAC) entre as três espécies, nin, fícus e acássia, com software ASSISTAT. Pesquisa sobre o microclima abaixo das copas de três espécies de eucaliptos foi realizada por Schumacher e Poggiani (1993) que compararam as médias de luminosidade, usando um luxímetro eles realizaram medições dentro e fora dos povoamentos em um dia com céu limpo sempre as 13:00 hs. Para a temperatura do subsolo eles realizaram medições a 5, 10 e $20 \mathrm{~cm}$ de profundidade utilizando um geotermômetro com leituras realizadas de hora em hora ao longo do dia, fornecendo 13 leituras diárias.

Nesta pesquisa, todas as temperaturas observadas nas três árvores fícus que estavam dentro do perímetro da copa foram consideradas amostra para aquela espécie e assim foi feito para cada uma das outras duas espécies (Cássia e Nin).

Para a comparação entre os tamanhos dos raios das copas, todas as temperaturas observadas em qualquer uma das nove árvores foram agrupadas em duas classes temperatura medida embaixo de árvore pequena, quando o raio da copa for $\leq 3,36$ metros e árvore grande quando o raio da copa for $\geq 4,20$ metros.

Foi feito comparações de média pelo teste de Tukey a amplitude da temperatura do solo abaixo da copa (ATSAC) para as três espécies e para os tamanhos dos raios das copas. Para o cálculo da amplitude foi utilizada a equação [1]. 


$$
A m=T_{i}-T_{m}
$$

Em que:

Am = Amplitude

$\mathrm{T}_{\mathrm{i}}=$ Temperatura no ponto $\mathrm{i}$

$\mathrm{i}=$ Ponto localizado no plano cartesiano $(\mathrm{X}, \mathrm{Y})$

$\mathrm{T}_{\mathrm{m}}=$ Menor temperatura abaixo da copa da árvore.

Foi construído o gráfico de dispersão relacionando o tamanho da copa com a temperatura média das medições mais próximas do tronco de cada árvore, a linha de tendência foi traçada e a equação de regressão foi construída.

\section{b) Geoestatística}

Foi construído o histograma para a TSAC para verificação de distribuição de probabilidade Segundo Cressie (1991) na geoestatística não é necessário que os dados tenham distribuição normal, porém é desejável que a possuam.

A espécie escolhida para construção do mapa de temperatura foi o fícus com raio de copa igual a 2,58 metros, isto foi baseado no censo das árvores das calçadas de Serra Talhada foi realizado por Lundgren et al. (2013) onde constataram que 68\% das árvores são fícus com raio de copa médio igual a 2,38 metros. Sendo assim a população de árvores desta espécie nas calçadas de Serra Talhada foi representada por esta medida de copa.

Em geoestatística é fundamental a construção do gráfico denominado de semivariograma amostral, esse gráfico permite verificar se a semivariância amostral depende da distância entre as medições realizadas. Para as análises e construção dos mapas foi utilizado o software GS+ versão 9. Landin (1998) apresenta toda a teoria matemática envolvida na construção do semivariograma que é calculado pela seguinte equação 2.

$$
Y(h)=\sum_{i=1}^{N_{h}} \frac{1}{2 N(h)}\left[Z_{x_{1}}-Z_{x_{i}+h}\right]^{2}
$$

Em que:

$\mathrm{Y}=$ semivariância amostral

$\mathrm{h}=$ distância

$\mathrm{N}(\mathrm{h})$ = números de pontos com $\mathrm{h}$ distância 
$Z_{\mathrm{xi}}=$ valor do atributo medido no ponto $\mathrm{x}_{\mathrm{i}}$

$\mathrm{x}_{\mathrm{i}}=$ ponto marcado no plano cartesiano

$\mathrm{x}_{\mathrm{i}}+\mathrm{h}=$ ponto com distancia $\mathrm{h}$ do ponto $\mathrm{x}_{\mathrm{i}}$

$Z_{x i+h}=$ valor do atributo medido no ponto $x_{i}+h$

Depois que as semivarâncias são calculadas para as distâncias padronizadas pelo pesquisador, o semivariograma pode ser construído. A construção do semivariograma permite a visualização da existência ou não da dependência espacial, ou seja, se for verificado que com o aumento da distância o valor da semivariância também aumenta (diretamente proporcional) ou diminui (inversamente proporcional), a dependência espacial existe e nesse caso é possível o uso da geoestatística. Um semivariograma típico tem a forma do gráfico da figura 2.

Figura 2. Esquema de um semivariograma típico

Figure 2. Schematic of a typical semivariogram

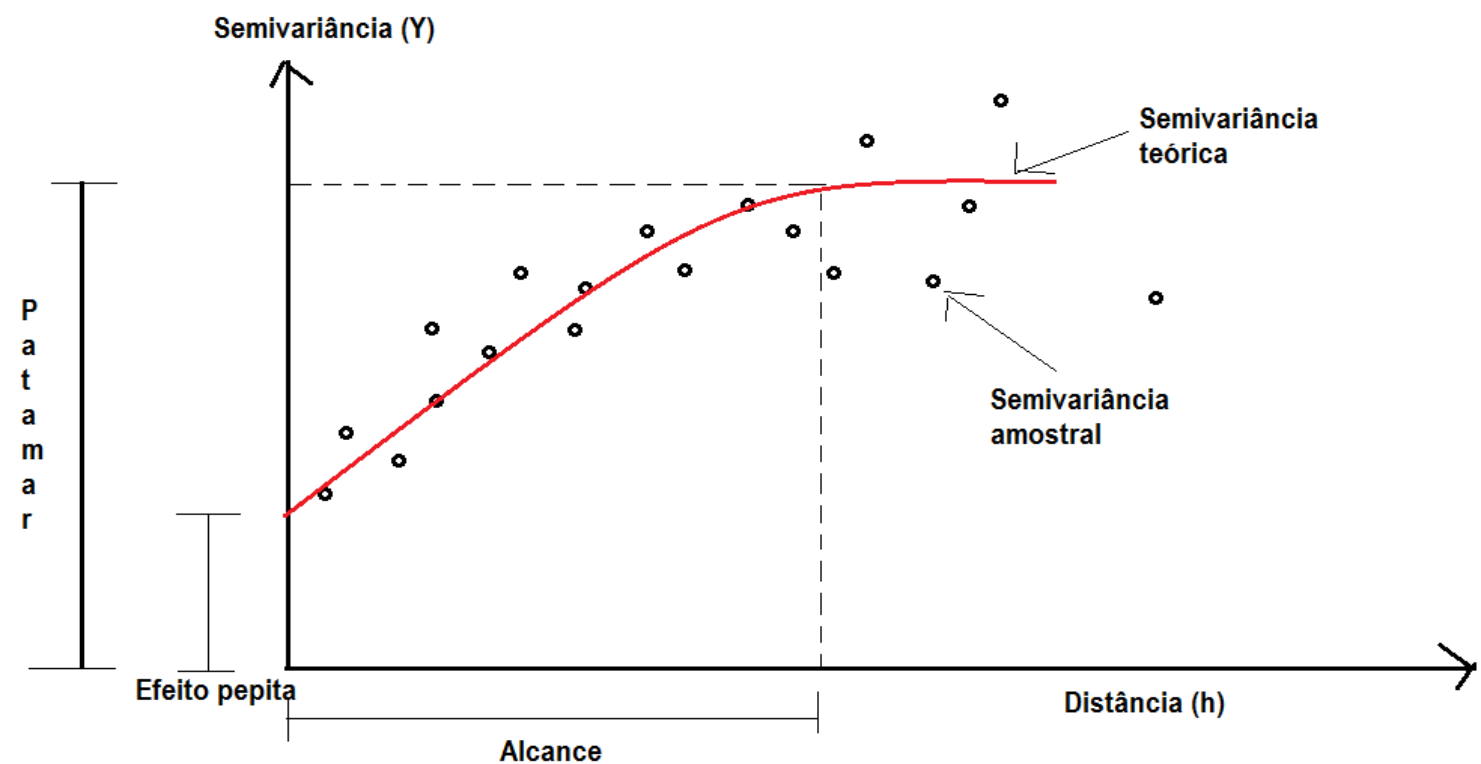

Nota: Alcance = distância máxima em que ainda encontra-se influência para o valor da semivariância. Patamar = valor máximo da semivariância para o valor do alcance. Efeito pepita = valor da semivariância quando a distância é zero

Para quantificar a dependência espacial Grego e Vieira (2005) utilizaram a razão de dependência (RD) que é calculada pela fórmula [3] que segundo Cambardella et al. (1994) se o $\mathrm{RD} \leq 25 \%$ há dependência espacial forte, se $25 \%<\mathrm{RD} \leq 75 \%$ existe dependência espacial moderada e RD > 75\% existe dependência espacial fraca. 


$$
R D=\frac{C_{0}}{p} \times 100
$$

Em que:

$\mathrm{C}_{0}=$ efeito pepita

$\mathrm{P}=$ Patamar

Existem alguns modelos de semivariogramas teóricos que explicam 0 comportamento da semivariância amostral. Lundgren (2004) apresentou onze modelos, todos os modelos utilizam três parâmetros: o alcance $(A)$, efeito pepita $\left(C_{0}\right)$ e o patamar $(P)$. O efeito pepita é considerado o erro obtido devido às microvariações ou falhas no equipamento de medição.

Quando o semivariograma amostral assume o mesmo comportamento para todas as direções da área estudada, a isotropia é confirmada, e nesse caso, é adotado um modelo único para as análises geoestatísticas. Porém quando para iferentes direções existem semivariogramas amostrais com diferentes comportamentos é considerada a existência da anisotropia, sendo necessário adotar diferentes modelos para diferentes direções.

Para verificar a existência de anisotropia usualmente procede-se da seguinte maneira: constrói-se semivariogramas amostrais para quatro diferentes direções, por exemplo: $0^{\circ}, 45^{\circ}, 90^{\circ}$ e $135^{\circ}$ e verifica-se visualmente se existe comportamento diferente entre eles (valores do efeito pepita, patamar, e alcance, além da estrutura visual dos pontos amostrais da semivariância).

Para a construção de mapas, que é o objetivo final da geoestatística, é necessário que os dados não apresentem tendência. A tendência ocorre quando os valores do atributo estão correlacionados com uma ou mais direções existentes na área em estudo. Para verificação de tendência são construídos dois gráficos de dispersão, um relacionando os valores do atributo com os valores do eixo da abscissa ( $X$ ou latitude) e o outro relacionando os valores do atributo com os valores da ordenada ( $Y$ ou longitude). Se o gráfico apresentar estrutura de correlação não nula é considerada a existência de tendência.

A análise de tendência é explicada por Landin e Corsi (2001), que demostraram como detectar a tendência e sua retirada usando regressão uma superfície contínua é ajustada por mínimos quadrados aos valores amostrados do atributo como uma função linear das coordenadas $\mathrm{X}-\mathrm{Y}$ dos pontos amostrados e irregularmente distribuídos. Os resíduos podem ser encontrados e retirados dos mapas.

Realizadas as análises geoestatísticas descritas anteriormente, é possível a construção de mapas do atributo usando o método de interpolação, conhecido como 
krigagem, que estima o valor do atributo em um ponto determinado usando a informação dos atributos nos pontos vizinhos e a distância existente entre esses pontos. Todo o processo matemático que envolve a geoestatística foi descrito inicialmente por Matheron (1971) e a equação é a seguinte:

$$
\ddot{Z}_{x_{0}}=\sum_{i=1}^{n} \lambda_{i} Z_{x_{i}}
$$

Em que:

$\hat{Z}_{\mathrm{xo}}=$ valor estimado do atributo no ponto $\mathrm{x}_{\mathrm{o}}$

$\lambda_{\mathrm{i}}=$ peso da interpolação para o ponto $\mathrm{i}$

$Z_{x i}=$ valor amostrado do atributo no ponto $x_{i}$

É necessário que a exigência [5] seja satisfeita.

$$
\sum_{i=1}^{n} \lambda_{i}=1
$$

Após a construção dos mapas do atributo é necessário verificar o quanto o mapa se aproxima da realidade, em outras palavras é preciso quantificar o erro cometido pela krigagem.

A validação cruzada foi o processo utilizado nesta pesquisa para verificação da qualidade da estimativa da krigagem. Esse método também foi utilizado por Mello et al. (2008) na verificação da continuidade espacial de chuvas no Estado de Minas Gerais. O método consiste em retirar o valor amostrado de um atributo em um ponto conhecido e estimar o valor do atributo pela krigagem como se ele não fosse conhecido e repetir o processo para todos os pontos conhecidos. O resultado é apresentado em gráfico de valores observados versus valores estimados.

\section{RESULTADOS E DISCUSSÃO}

A Tabela 1 apresenta o comprimento dos raios e os espaçamentos entre os pontos de medição das temperaturas em baixo das nove árvores usadas na atual pesquisa. 
Tabela 1. Características das nove árvores amostradas na pesquisa

Table 1. Characteristics of the nine trees sampled in the survey

\begin{tabular}{ccccc}
\hline Espécie & Amostras & $\begin{array}{c}\text { Raio da } \\
\text { copa }(\mathrm{m})\end{array}$ & $\begin{array}{c}\text { Espaçamento entre } \\
\text { medições }(\mathrm{m})\end{array}$ & $\begin{array}{c}\text { Média da copa por } \\
\text { espécie }(\mathrm{m})\end{array}$ \\
\hline Ficus & 1 & 4,38 & 0,73 & 3,40 \\
benjamina & 2 & 2,58 & 0,43 & \\
& 3 & 3,24 & 0,54 & 3.92 \\
Acacia & 1 & 3,00 & 0,50 & \\
farnesiana & 2 & 5,40 & 0,90 & 4,50 \\
\hline \multirow{2}{*}{ Azadirachta } & 3 & 3,36 & 0,56 & \\
indica & 1 & 4,80 & 0,80 & \\
& 2 & 4,50 & 0,75 & \\
\hline
\end{tabular}

\section{Estatística clássica}

\section{a) Histograma}

$\mathrm{Na}$ verificação de normalidade dos dados de temperatura do solo abaixo de cada árvore o primeiro passo foi a construção do histograma.

O histograma construído com as 53 medições de temperatura medidas abaixo do fícus com raio de copa =2,58 metros entre 11:30 e 12:30 do dia, não esboçou a forma de normalidade dos dados que é a forma de sino (Figura 3). Duas transformações foram tentadas, a transformação logarítmica e a raiz quadrada, porém nenhuma delas conseguiu normalizar os dados. Assim, nenhum teste de normalidade foi realizado, pois se o gráfico não apresenta a forma de normalidade não é necessário verificar essa característica.

Figura 3. Temperatura abaixo da copa do fícus com raio $=2,58$ metros

Figure 3. Temperature below the canopy ficus with radius $=2,58$ meters

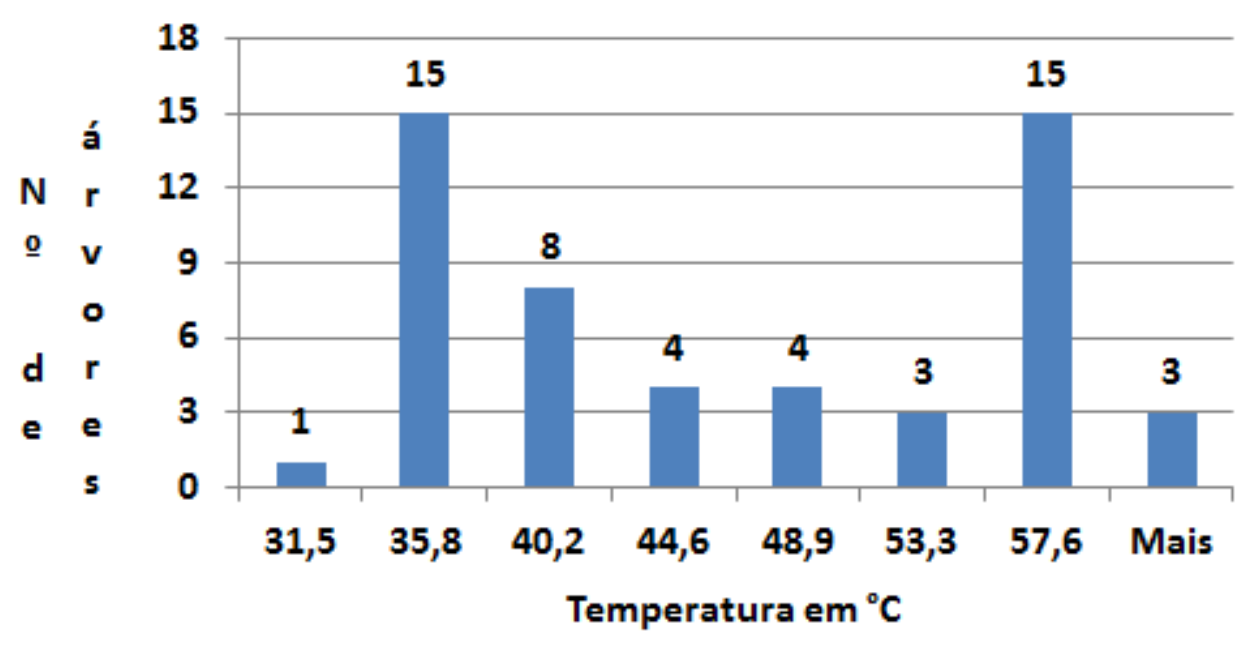


A temperatura do solo também foi pesquisada por Furlani et al. (2008), eles pesquisaram sobre a influência do preparo do solo na temperatura do solo ao longo do dia, eles chegaram a conclusão de que para todos os preparos a temperatura mais alta do sol era sempre as 15:00 hs e temperatura mais baixa as 7:00 hs.

A informação sobre a distribuição de probabilidade ser ou não normal, é de interesse da geoestatística, segundo Anadriotti (2002) quando os dados possuem a distribuição normal os erros cometidos na estimativa espacial são menos tendenciosos.

\section{b) Espécies X Temperatura}

Na comparação entre as espécies quanto a temperatura abaixo da árvore o teste de Tukey não detectou diferença significativa ao nível de $5 \%$ entre as espécies visto que o teste forneceu $p$-valor $=0,31$.

\section{c) Espécies X Amplitude térmica}

Quando foi comparado a amplitude térmica entre as espécies, houve diferença significativa onde $p$-valor $=0,001$. A Tabela 2 apresenta os resultados da comparação das médias das amplitudes para a espécie.

Tabela 2. Média das amplitudes térmicas por espécies

Table 2. Average temperature ranges by species

\begin{tabular}{lcl}
\hline Espécie & Média $\left({ }^{\circ} \mathrm{C}\right)$ & Agrupamento \\
\hline acássia & 15,38 & a \\
nin & 13,73 & a,b \\
fícus & 10,85 & b
\end{tabular}

Nota: Letras iguais na linha vertical são consideradas populações iguais

A diferença de amplitude térmica entre a acássia e o fícus não era esperada, o fícus possui copa densa onde os raios do sol tem dificuldade de penetração, portanto a temperatura na área sombreada deveria ser menor do que as temperaturas abaixo das acássias e as temperaturas nas áreas ensolaradas deveriam ser iguais para as duas espécies, ou seja, a temperatura mínima na espécie fícus deveria ser menor do que na espécie acássia e as temperaturas máximas deveriam ser iguais, já que estão ambas nas áreas ensolaradas. 
Uma possível explicação para o comportamento inesperado da amplitude térmica poderia ser a menor dimensão da copa dos fícus $(3,40 \mathrm{~m})$ em relação as acássias $(3,90 \mathrm{~m})$, como pode ser visto na Figura 6 quanto maior a copa, menor a temperatura próxima ao caule. Porém essa explicação deve ser descartada, pois como pode ser visto na tabela 1, a copa média do nin é a maior de todas e não foi constatada diferença para a amplitude térmica entre o nin e o fícus como pode ser observada na tabela 2.

O resultado para o nin era esperado e pode ser explicado por essa espécie possuir copa de tamanho intermediário entre as outras duas espécies. O conceito de copa rala ou fechada é discutido por Vasconcelos (2011) em que ela classifica a copa da árvore pelo percentual de luminosidade que atravessa a copa. Na atual pesquisa foi levado em conta apenas o tamanho das copas.

Observando os gráficos da Figura 4, pode-se perceber que a diferença entre as médias das temperaturas abaixo das copas das árvores é mínima, e o teste de Tukey não identificou diferença entre elas. Quando se observa para as médias das amplitudes térmicas abaixo das copas das espécies de árvores percebe-se que a diferença entre as médias da acássia e do fícus é próxima a cinco graus, uma diferença significativa tanto estatisticamente quanto para a sensação térmica de quem escolher se abrigar em uma ou outra.

Figura 4. Médias das temperaturas e médias das amplitudes térmicas por espécies

Figure 4. Mean average temperatures and thermal amplitudes by species

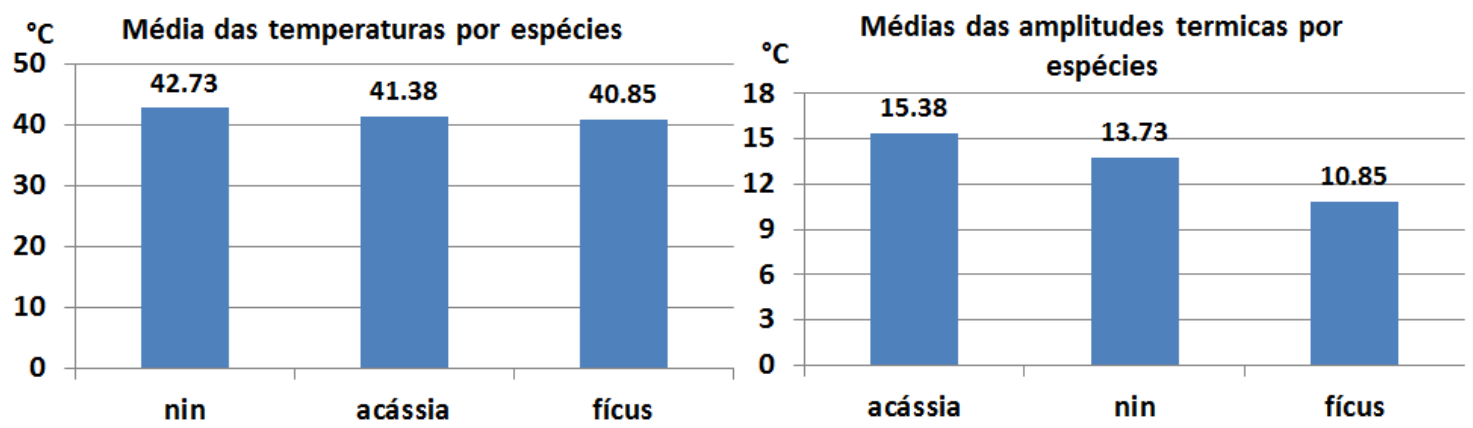

Foi comparada também a dimensão da copa quanto sua influência na temperatura abaixo da árvore, ou seja, nessa comparação não foi levado em conta as medições de temperatura realizadas ao sol. Para a temperatura abaixo da árvore foram criadas duas populações, uma de árvores pequenas, essas com os raios de copa de 2,38 m, 3,00 m, 3,24 $\mathrm{m}$ e 3,36 m e as grandes com copas de 4,20 m, 4,38 m, 4,50 m 4,80 m e 5,40 m foram usadas todas as medições de temperatura efetuadas em cada uma das árvores, não houve 
diferença estatística entre as árvores com copas grandes e copas pequenas, em que o pvalor $=0,75$. Todas as árvores forneceram temperaturas semelhantes que estão em torno de $30^{\circ} \mathrm{C}$ para as temperaturas mais baixas e a mais alta em torno de $58^{\circ} \mathrm{C}$. O resultado obtido de não diferenciação para o atributo temperatura não é surpresa.

\section{e) Dimensão da copa X Amplitude térmica}

Para a amplitude térmica foi detectada diferença estatística entre as copas pequenas e grandes a um $p$-valor $=0,02$. Para cada uma das medições de temperaturas efetuadas, 0 valor medido foi diminuído da menor temperatura encontrada para aquela árvore, esse valor em todos os casos foi aquele medido próximo ao tronco, todas as amplitudes conseguidas para as árvores pequenas, aquelas com raios de copa $(2,38 \mathrm{~m}, 3,00 \mathrm{~m}, 3,24 \mathrm{~m}$ e 3,36 m) foram comparadas com todas as amplitudes conseguidas para as grandes árvores com copas de 4,20 m, 4,38 m, 4,50 m 4,80 m e 5,40 m, nas medições efetuadas cada vez mais longe do tronco, a temperatura tendia a aumentar, provocando, portanto, aumento da amplitude para as árvores maiores, fato que foi detectado pelo teste estatístico. A figura 5 mostra a média de temperatura e a média das amplitudes para os dois tamanhos da copa.

Figura 5. Médias de temperatura e amplitude térmica para as dimensões das copas das árvores

Figure 5. Mean temperature and temperature range for the size of the canopy trees

\begin{tabular}{|c|c|c|c|c|c|}
\hline \multicolumn{3}{|c|}{ temperaturas } & \multicolumn{3}{|c|}{ amplitudes térmicas } \\
\hline 50,00 & 41,48 & 41,80 & 15,00 & & 12,42 \\
\hline 40,00 & & & & 10,07 & \\
\hline 30,00 & & & 10,00 & & \\
\hline 20,00 & & & & & \\
\hline \multirow{3}{*}{$\begin{array}{r}10,00 \\
0,00\end{array}$} & & & (ס) & & \\
\hline & & & 0,00 & & \\
\hline & Pequena & Grande & & Pequena & Grande \\
\hline
\end{tabular}

Quando se analisa a amplitude térmica, quanto maior a copa, maior a diferença entre a temperatura próxima ao tronco e a do limite externo da copa. Existe uma tendência de que as temperaturas junto ao tronco sejam cada vez menores a medida que a copa é maior.

$\mathrm{Na}$ (Figura 6), observa-se que o coeficiente de inclinação na equação de regressão é negativo, indicando correlação negativa entre tamanho da copa e temperatura próxima ao tronco. 
Figura 6. Raio das copas das árvores $\mathrm{x}$ a temperatura média de cada árvore na medição mais próxima ao tronco

Figure 6. Ray of the trees $x$ the average temperature of each tree in the measurement closest to the trunk

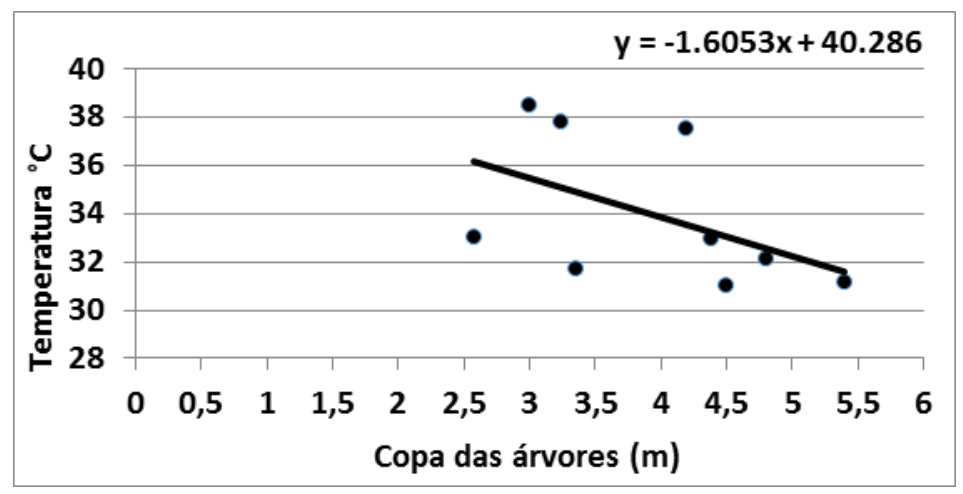

Portanto, para as árvores grandes é esperado que a amplitude térmica seja maior que nas árvores pequenas, isso se deve ao fato que as temperaturas no solo próximas ao tronco diminuem a medida que a copa da árvore aumenta, então teremos as menores temperaturas nas maiores árvores, por outro lado as maiores temperaturas são sempre encontradas na fronteira entre a sombra da árvore e a calçada banhada pelo sol pleno, e essa temperatura máxima pouco varia para qualquer que seja a árvore, a temperatura máxima tende a se estabilizar próxima da temperatura do solo a descoberto (temperaturas máximas variando entre $55^{\circ} \mathrm{C}$ e $62^{\circ} \mathrm{C}$ ). Fravetto e Chvatal, (2011) compararam a temperatura e a amplitude térmica do ar abaixo de três espécies de árvores na cidade de São Carlos - SP e constataram que havia diferença significativa entre as espécies.

\section{Geoestatística}

Foi construído apenas um mapa de temperatura abaixo da árvore, na análise estatística clássica o interesse foi mostrar o comportamento da temperatura do solo abaixo da copa das árvores, ou seja, na área sombreada. Os mapas construídos pela técnica krigagem utilizaram tanto as coletas abaixo da copa como também coletas ao redor da árvore onde o sol bate diretamente no solo, com o interesse de mostrar o quanto de temperatura uma árvore de pequeno porte consegue diminuir com a sua copa. 


\section{a) Análise de anisotropia}

O semivariograma é o primeiro passo a ser realizado depois de se verificar se os dados tem distribuição normal. Quatro semivariogramas foram construídos para testar a anisotropia cada um deles em uma direção expressa em graus $0^{\circ}$; 45ㅜ; $90^{\circ}$ e $135^{\circ}$ (Figura 7).

Figura 7. Semivariogramas amostrais anisotrópicos

Figure 7. Anisotropic sample semivariogram

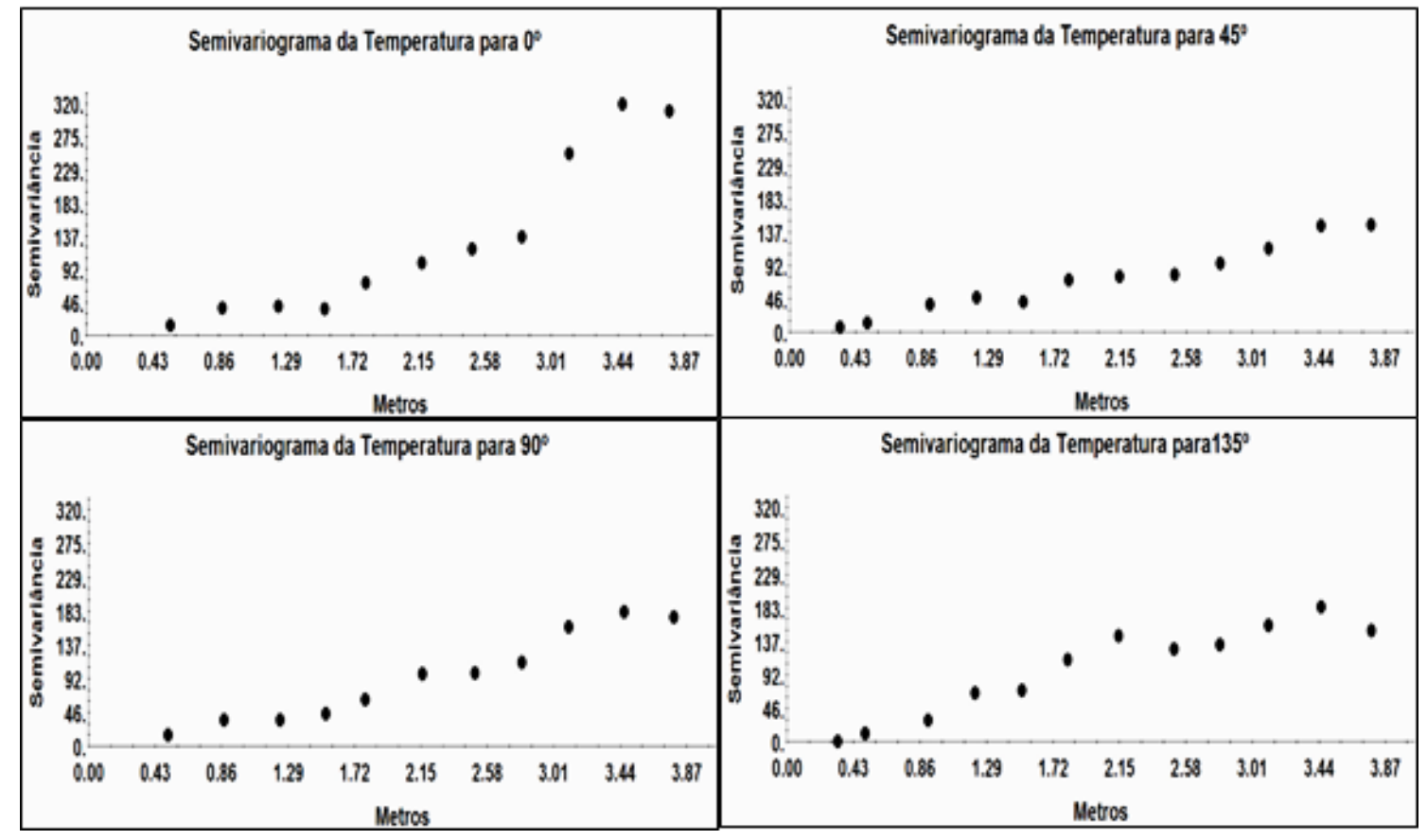

O comportamento dos semivariogramas não apresenta diferenças estruturais entre eles, os parâmetros patamar, alcance e efeito pepita são semelhantes. Nota-se uma acentuada inclinação para a direção $0^{\circ}$ quando a distância ultrapassa os três metros em relação a outras direções, porém nada que indique a necessidade de se assumir um semivariograma espécifico para essa direção. Descartada a anisotropia, um semivariograma isotrópico foi construído e foi assumido um modelo isotrópico (Figura 8). 
Figura 8. Semivariograma Isotrópico da temperatura

Figure 8. Isotropic Temperature Semivariogram

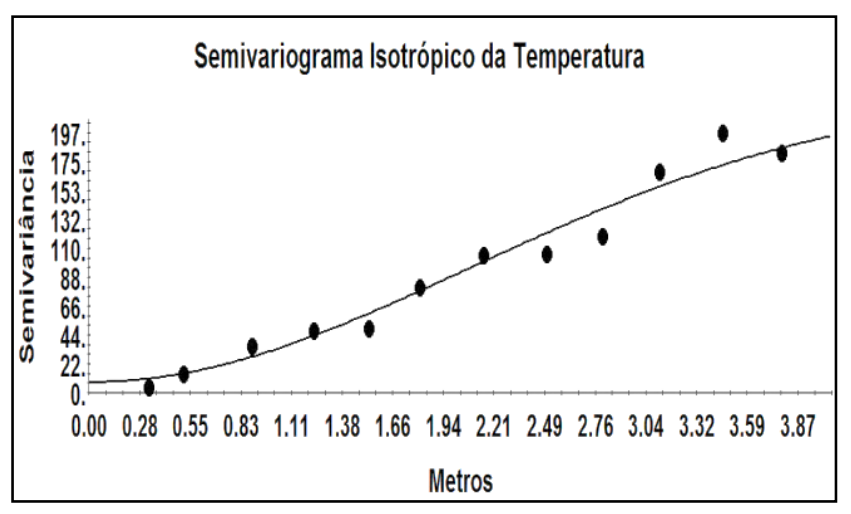

A dependência espacial foi comprovada, ou seja, a temperatura do solo em um determinado local sofre influência das temperaturas vizinhas a sua volta. Para medir a intensidade da dependência espacial foi calculado o RD utilizando a equação [3] que forneceu valor igual a 3,4\%, indicando que existe uma forte dependência espacial.

Ramos et al. (2011) encontraram dependência espacial para a temperatura do ar de duas cidades, Petrolina - PE e Botucatu - SP e construíram mapas de krigagem para o atributo temperatura do ar, eles não comentam se encontraram ou não anisotropia.

A característica no semivariograma isotrópico amostral que chama a atenção e que merece uma preocupação a mais nas estimativas da temperatura a serem realizadas, é a ausência do parâmetro patamar, a ausência do patamar segundo Silva et al. (2008) indica a existência de tendência para os dados.

O modelo de semivariograma teórico foi o Gaussiano, com o efeito pepita $=7,80$; patamar $=226,50$ e alcance $=2,92 ;$ o $R^{2}=0,964$.

\section{b) Análise de tendência}

Os gráficos de dispersão para os eixos $X$ e $Y$ versus a temperatura foram construídos e apresentaram tendências. A tendência é observada quando os pontos do gráfico apresentam forma estruturada, forma não dispersa (Figura 9). 
Figura 9. Gráficos de dispersão para os eixos $\mathrm{X}$ e $\mathrm{Y}$ versus a temperatura abaixo das árvores

Figure 9. Scatter plots for the $\mathrm{X}$ and $\mathrm{Y}$ axis versus temperature below trees

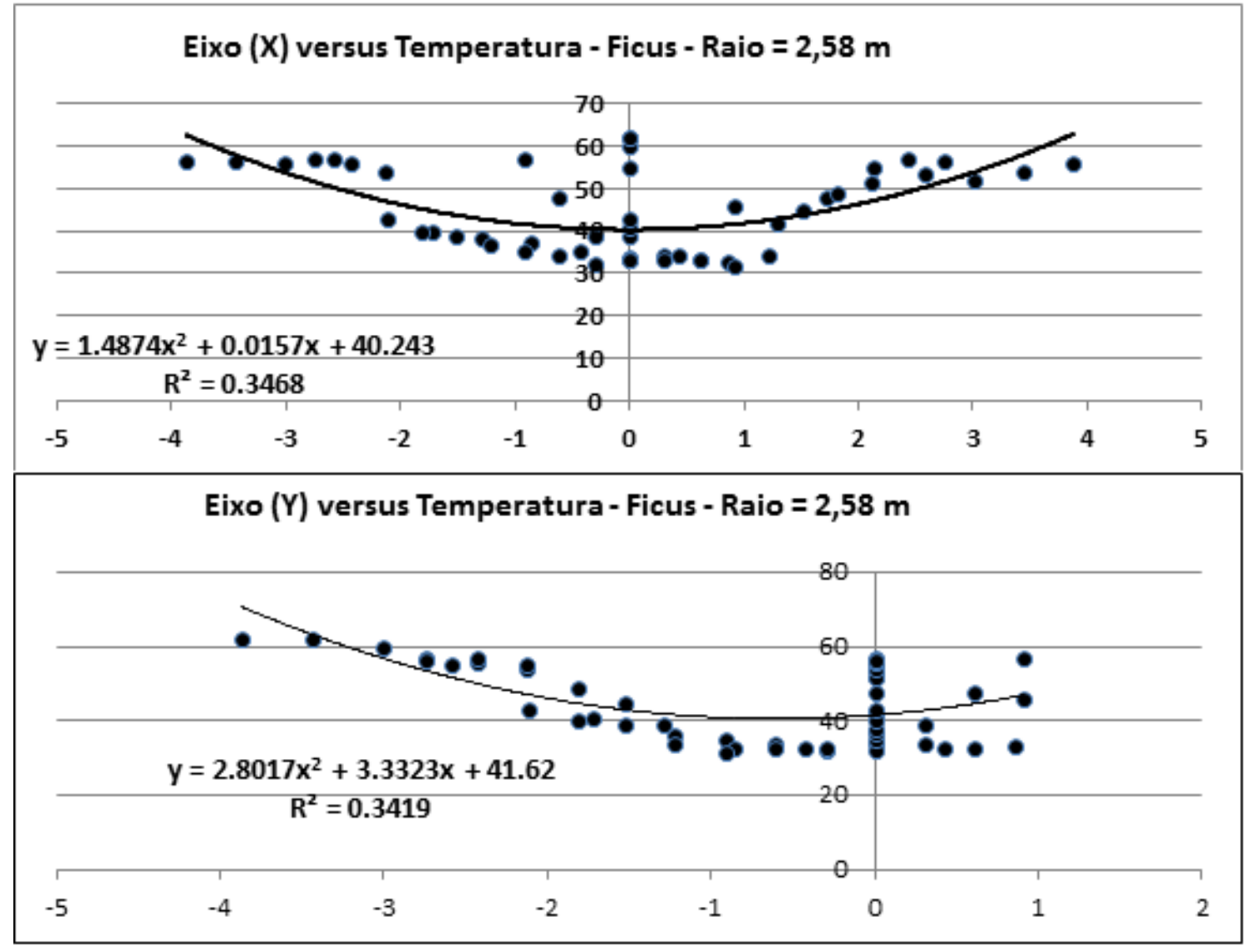

A tendência dos dados foi comprovada, porém as medianas para o eixo $X \circ R^{2}=$ 0,34 e para o eixo $Y \circ R^{2}=0,34$ e para os dois eixos a linha de tendência é polinomial quadrática, os modelos utilizados para a retirada das tendências estão explicitados nos gráficos apresentados na Figura 9.

\section{c) Krigagem}

Depois de realizadas as análises, escolhido o modelo e retirada a tendência dos dados foi possível efetuar a kigragem e construir o mapa da temperatura em volta da árvore (Figura 10). 
Figura 10. Mapa da temperatura construído por krigagem

Figure 10. Temperature map constructed by kriging

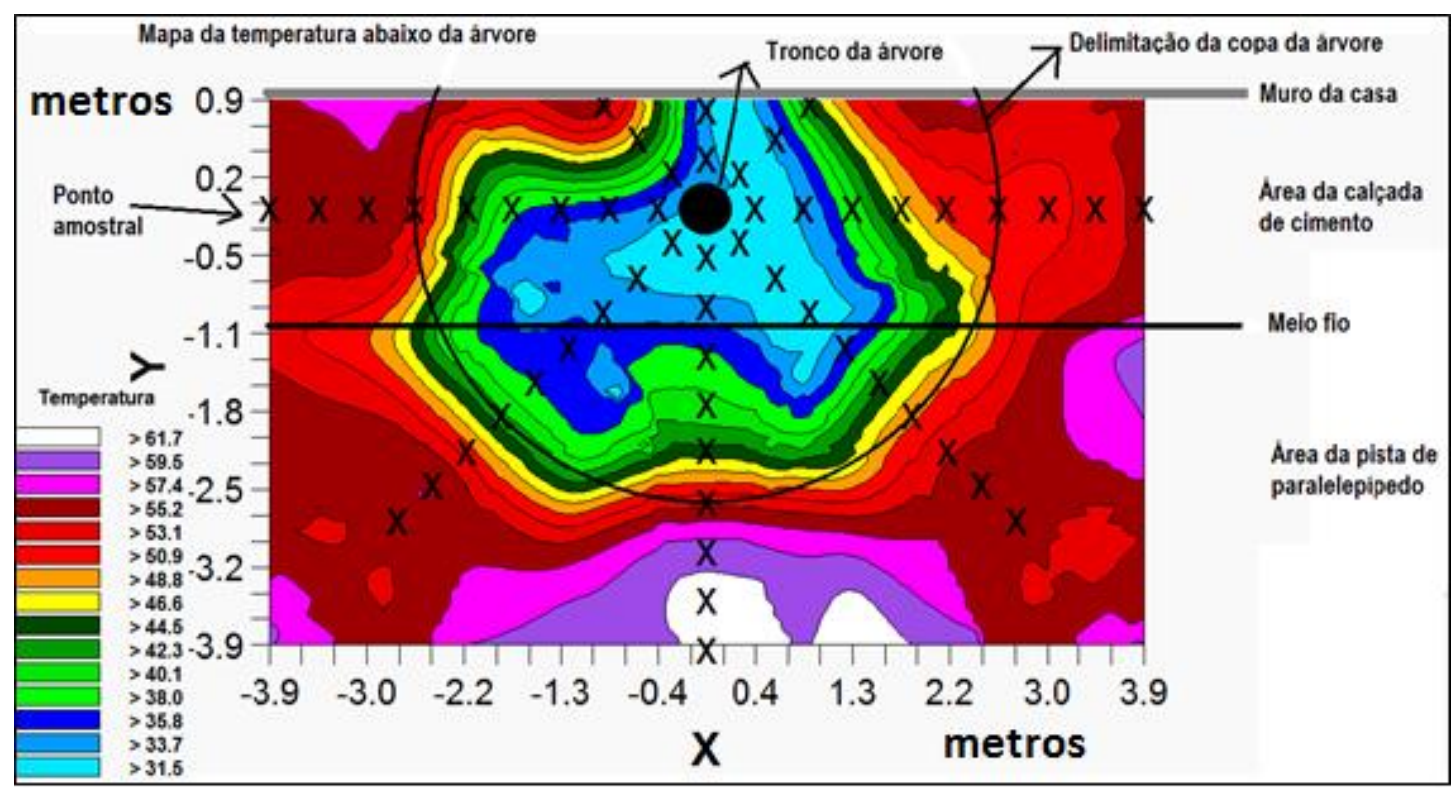

A amplitude térmica encontrada entre as temperaturas próximas ao tronco e as temperaturas dos paralelepípedos que recebiam o sol pleno em volta da árvore, foi inesperadamente muito alta $\left(30^{\circ} \mathrm{C}\right)$, antes das medições intuitivamente os pesquisadores acreditavam que essa diferença seria no máximo de $12^{\circ} \mathrm{C}$. Resultado semelhante foi percebido por Nunes (2004) na região de Évora em Portugal, que entre outras medições mediu a temperatura do solo nas áreas dentro e fora da projeção vertical da copa da espécie Quercus rotundifolia, ele percebeu que invariavelmente a temperatura de fora era superior a temperatura de dentro, e que no inverno a temperatura de fora chegou a ser 0 dobro da de dentro.

As áreas sob a sombra das árvores coincidiram com as áreas de tonalidade azul no mapa apresentado na Figura 10, as áreas em azul possuem temperaturas mais baixas. 0 limite da copa (Delimitação da copa da árvore) coincide na maioria das vezes, com as cores amarelas, laranja e vermelho claro, que são as temperaturas intermediárias.

Nota-se também que o aquecimento aumenta com distâncias maiores acompanhando o eixo $\mathrm{X}$ e na proximidade do meio fio, porém no sentido do eixo $\mathrm{Y}$ vindo do tronco em direção perpendicular ao meio fio, as temperaturas mudam com menor espaçamento. Uma possível explicação para esse fato é a densidade do paralelepípedo e sua cor mais escura que favorece o maior aquecimento deste em comparação com o aquecimento do cimento que compõe a calçada.

O gráfico apresentando os valores de temperatura observados $\mathrm{x}$ estimados é apresentado na figura 11. 
Figura 11. Temperaturas observadas e estimadas pela krigagem

Figure 11. Temperatures observed and estimated by kriging

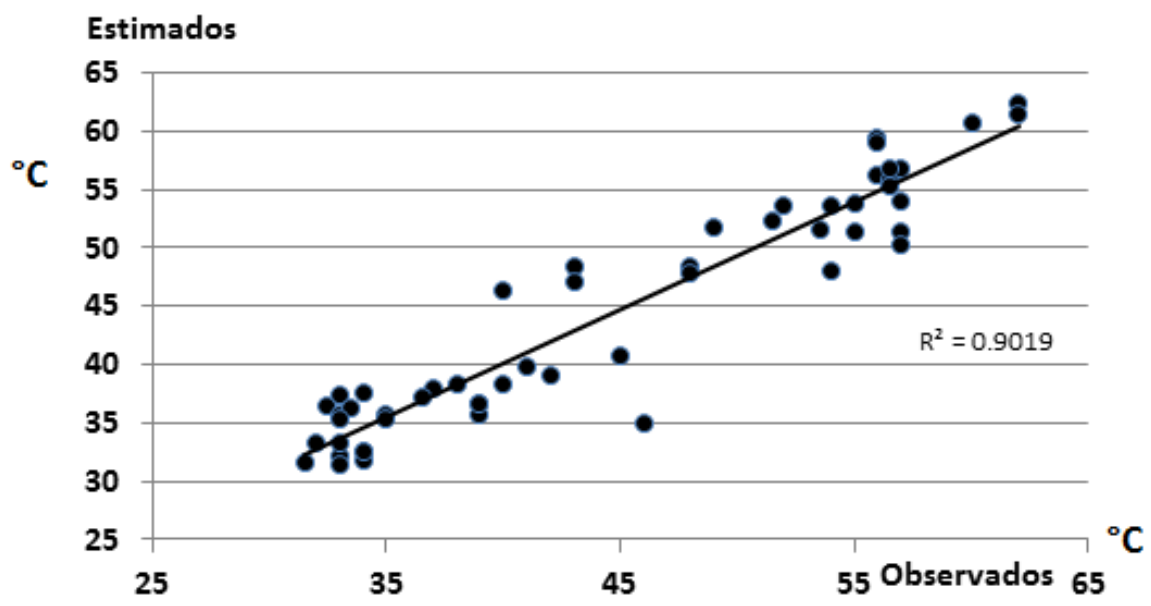

O valor do $R^{2}$ foi de 0,90 indicando que as estimativas foram boas, ficando bem próximas das verdadeiras temperaturas medidas em campo.

\section{CONCLUSÕES}

Não existe diferença estatística entre as temperaturas do solo abaixo das copas das três espécies testadas. No entanto, a amplitude térmica da temperatura do solo abaixo das copas das árvores é influenciada pela espécie, sendo a acássia a espécie com maior amplitude.

O tamanho da copa da árvore não interfere nas temperaturas médias do solo abaixo da copa, mas a amplitude térmica do solo abaixo das copas das árvores é influenciada pela dimensão da copa.

A temperatura próxima ao tronco é inversamente proporcional a dimensão da copa e a temperatura do solo abaixo da copa tem dependência espacial.

\section{REFERÊNCIAS}

ANADRIOTTI, J. L. S. Notas de Geoestatística. Rev. Acta Geologica Leopoldensia. N. XXV, Vol. 55, p. 3 - 14, 2002. Disponível em: http://www.cprm.gov.br/publique/ media/Art_Andriotti_notas_geoestatistica.pdf. Acesso em: 06/12/2013.

CAMBARDELLA, C. A.; MOORMAN, T. B.; NOVAK, J. M.; PARKIN, T. B.; KARLEN, D. L.; TURCO, R. F.; KONOPKA, A. E. Field-scale variability of soil properties in central lowa soils.

Soil Science Society America Journal, Madison, v.58, n. 4, p.1501-1511, 1994. 
CRESSIE, N. Statistics for Spatial Data. Chichester: John Wiley. 1991.

FRAVETTO, A. P. O. e CHVATAL, K. M. S. Contribuições para o conforto térmico urbano: caracterização de espécies arbóreas na cidade de São Carlos, SP. XI ENCAC - Encontro Nacional de Conforto Térmico no Ambiente Construído. VII ELACAC - Encontro Latino Americano de Conforto no Ambiente Construído. Búzios - RJ. 2011.

FURLANI, C.E.A.; GAMERO,C.A.; LEVIEN, R.; SILVA, R. P. da; CORTEZ, J.W. Temperatura do solo em função do preparo do solo e do manejo da cobertura de inverno. $\mathbf{R}$. Bras. Ci. Solo, v. 32, p. 375-380, 2008.

GOMES, M. A. S. e SOARES, B. R. A vegetação nos centros urbanos: considerações sobre os espaços verdes em cidades médias brasileiras. Rev. Estudos Geográficos, Rio Claro, v.1, n. 1, p. 19-29, Junho, 2003.

GOUVEIA, N. Saúde e meio ambiente nas cidades: os desafios da saúde ambiental. Rev. Saúde e Sociedade, São Paulo, v.8, n.1, p. 49-61, 1999.

GREGO, C. R. e VIEIRA, S. R. Variabilidade espacial de propriedades físicas do solo em uma parcela experimental. Rev. Brasileira de Ciências do Solo, n. 29, p. 169-177, 2005.

IBGE - INSTITUTO BRASILEIRO DE GEOGRAFIA E ESTATÍSTICA. Censo Demográfico de 2010. Disponível em: http://censo2010.ibge.gov.br/images/pdf/censo2010/ questionario/questionario_amostra_cd2010.pdf. Acesso em: 17/12/2013.

LANDIN, P. M. B. Análise Estatística de Dados Geológicos. São Paulo: Ed. Fundação Editora da UNESP. 63p., 1998.

LANDIN, P. M. B.; CORSI, A.C. Cálculo de superfícies de tendência, por regressão polinomial, pelo SURFER 6. DGA, IGCE, UNESP/Rio Claro, Lab. Geomatemática, Texto Didático 05, 11 pp. 2001. Disponível em: <http: //www.rc.unesp.br/igce/ aplicada/textodi.html.> Acesso em: 02/12/2013.

LUNDGREN, G. A.; LUNDGREN, W. J. C.; SILVA, L. F. da; ALMEIDA, A. Q.; SANTOS, K. S.; SILVA, M. A. da; PEDROSA, P. E. R. Uso do ArcGis na arborização da cidade de Serra Talhada - PE. XII Jornada de Ensino, Pesquisa e Extensão - JEPEX - UFRPE. 26 a 30 de novembro de 2012.

LUNDGREN, W. J. C.; SILVA, L. F. da; ALMEIDA, A. Q. Influência das espécies exóticas arbóreas urbanas na área de cobertura da cidade de Serra Talhada - PE. REVSBAU, Piracicaba - SP, v.8, n.3, p 96-107, 2013.

LUNDGREN, W. J. C. Uso da co-krigagem na caracterização da variabilidade espacial da condutividade hidráulica. Dissertação de Mestrado em Bioestatística. UFRPE Universidade Federal Rural de Pernambuco. 2004. 
MATHERON, D. F. Traité de Geostatistique Appliquée. Technip. 2v., 1962 - 1963. The Theory of Regionalized Variables and its Applications. Centre Geoestatistique (Fontainebleau, France), 1971.

MELLO, C. R. de; VIOLA, M. R.; MELLO, J. M. de; SILVA, A. M. da. Continuidade espacial de chuvas intensas no estado de Minas Gerais. Rev. Ciência e Agrotecnologia, Lavras, v. 32 , n. 2, p. 532-539, 2008.

MENDONÇA, F. e DUBREUIL, V. Termografia de superfície e temperatura do ar na RMC (região metropolitana de Curitiba/PR). Editora UFPR, Curitiba, n. 9, p. 25-35, 2005. Disponível em: <http://ojs.c3sl.ufpr.br/ojs-2.2.4/index.php/raega/article/view/ 3444/2721.> Acesso em: 17/12/2013.

M.M.E. MINISTÉRIO DAS MINAS E ENERGIA. Diagnóstico do município de Serra Talhada. Projeto cadastro de fontes de abastecimento por água subterrânea. 2005. Disponível em: <http://www.cprm.gov.br/rehi/atlas/pernambuco/relatorios/SETA1 48.pdf.> Acesso em 09/11/2013.

NUNES, J. Interacção Solo Árvore Isolada em Montados de Azinho (Quercus rotundifolia Lam.): Processos Fundamentais. Dissertação de doutoramento, Évora, Universidade de Évora, 252 p. 2005.

RAMOS, C. M. C.; SILVA, A. F. da; SARTORI, A. A. da; ZIMBACK, C. R. L. e BASSOI, L. H. Modelagem da variação horária da temperatura do ar em Petrolina, PE, e Botucatu, SP. Revista Brasileira de Engenharia Agrícola e Ambiental. Campina Grande - PB. v.15, n.9, p.959-965, 2011.

SCHUMACHER, M. V. e POGGIANI, F. Caracterização microclimática no interior dos talhões de Eucalyptus camaldulensis dehnh, Eucalyptus Grandis hill ex maiden e Eucalyptus torelliana $f$. Muell, localizados em Anhembí, SP. Rev. Ciências Florestais, Santa Maria, v.3, n.1, p. 9-20, 1993.

SHAMS, J. C. A.; GIACOMELI, D. C. e SUCOMINE, N. M. Emprego da arborização na melhoria do conforto térmico nos espaços livres públicos. REVSBAU, Piracicaba - SP, v.4, n.4, p.1-16, 2009.

SILVA, A. R. da; GUIMARÂES, E. C.; TAVARES, M. Efeito de tendência no ajuste de semivariogramas esféricos. FAMAT em Revista, n. 10, p. 107 - 116, 2008.

VASCONCELLOS, V. M. N. de. Classificação sistemática das densidades de copa das árvores. VI Encontro Nacional e IV Encontro Latino-americano sobre Edificações e Comunidades Sustentáveis - Vitória - ES - BRASIL - 7 a. 9 de setembro de 2011. Disponível em: <http://www.elecs2013.ufpr.br/wp-content/uploads/anais/2011/2011_ artigo_047.pdf.> Acesso em: 10/12/2013. 